\title{
EFFECT OF $\alpha$-TOCOPHEROL ACETATE ON FECUNDITY AND REPRODUCTIVE PHYSIOLOGY OF OREOCHROMIS NILOTICUS AND O. AUREUS BROODSTOCK.
}

\author{
Gamal. A. Mohamed ', Mohamed E. Farag ' \\ and Salah A. Gabr ${ }^{2}$ \\ 1-Central Laborataory for Aquaculture Research \\ 2- Atomic Energy Authority
}

Key words: Oreochromis niloticus, Oreochromis aureus, fecundity, reproductive physiology, nutrition

\section{ABSTRACT}

study was conducted to determine the effect of vitamin
$\mathrm{E},(\alpha$-tocopherol acetate $\alpha-\mathrm{TOH})$ supplementation on the fecundity and reproductive performance of Nile tilapia Oreochromis niloticus and $O$. aureus. $\mathrm{R}$ eproductive performance was assessed in the females, in the developing eggs and in the resultant offspring, in an attempt to determine the optimum nutrition for successful spawning of $O$. niloticus and $O$. aureus. The reproductive response of $O$. niloticus and $O$. aureus to alpha-tocopherol acetate was nearly the same regarding egg number and quality, hatchability, gonadosomatic index and quality of the resulting offspring.

Results revealed that alpha-tocopherol acetate greatly improved not only egg and sperm quality but also seed production. None of the three levels of alpha-tocopherol acetate had any obvious effect on the mean relative fecundity of either $O$. niloticus or $O$. aureus. Females of both strains that fed on a diet supplemented with $50 \mathrm{mg} \mathrm{a}$ tocopherol acetate $/ \mathrm{kg}$ produced larger eggs than females of the control that fed on diet without supplemental alpha- 
tocopherol, or on diets supplemented with lower levels of $\alpha$ -TOH. The highest mean hatching percentage and lowest mean percentage of deformed larvae were observed in eggs extruded from females fed $50 \mathrm{mg} \alpha-\mathrm{TOH} / \mathrm{kg}$-supplemented diet in both strains. While lower mean values of hatching percentage and higher mean values of deformed larvae percentage were detectable in eggs of those females that were fed supplemental 25 and $5-\mathrm{mg} \alpha-\mathrm{TOH} / \mathrm{kg}$ diet. Fry of the third treatment attained the highest mean body weight. The smaller sizes of fry were obtainable from eggs produced by females fed the lower levels of $\alpha-\mathrm{TOH}$. Fry of females that fed tocopherol -free diet was the smallest. Females that fed on diets provided with higher levels of a:$\mathrm{TOH}$ not only produced larger eggs but also had higher mean values of GSI than those fed on diets with lower levels.

Irrespective of the supplemental $\alpha-\mathrm{TOH}$ levels that had no effect on the mean number of eggs/female in the three treatments of both strains, correlating the $O$. niloticus and $O$. aureus female body weight and the corresponding number of eggs, produced, showed a linear correlation. The equation of this relationship in the first spawning is represented as follows: $\mathrm{Y}=4.3353 \mathrm{X}-166.67$ for $O$. niloticus and $\mathrm{Y}=4.7819 \mathrm{X}-235.76$ for $O$. aureus, where $\mathrm{Y}=$ number of eggs and $\mathrm{X}=$ female body weight.

Further investigations are needed to estimate egg production/female in the following spawnings all over the reproductive period under the same conditions.

With regard to the reproductive hormones, concentration of luteinizing hormone $(\mathrm{LH})$ and follicle stimulating hormone (FSH) in serum of $O$. niloticus females of the third treatment, that exhibited more active reproductive performance, was higher than that in serum of females of the other treatments and the control. 


\section{EFFECT OF $\alpha$-TOCOPHEROL ACETATE \\ ON THE REPRODUCTIVE PHYSIOLOGY OF TILAPIA}

The results confirm the essentiality of vitamin $E$ supplementation in producing spawn with better egg and larval quality.

\section{INTRODUCTION}

The Nile tilapia. Oreochromis niloticus. is the most widely cultured tilapia in the world because of its rapid growth, late age of sexual maturity and planktivorous feeding habits (Lovshin. 1998). Methods of reproducing Oreochromis sp. are well-documented (Green et al. . 1997) and Macintosh and Little (1995). In Egyptian Delta, spawning of Tilapia may extend from April to November with a maximum spawning in early summer (El-Saby. 1951). Rising temperature to $20^{\circ} \mathrm{C}$ or higher triggers the spawning operations of Tilapia, which start in April or May (Mires. 1983). Number of eggs per spawn may differ among species, but within species the number of eggs increased with increasing weight of female (Badawy, 1993).

One of the most important requirements for the advancement of tilapia culture is the development of systems for mass production of seed; free-swimming fry, sac fry and eggs released from the female's mouth; (Hughes and Behrends. 1983). Therefore, a deeper attention should be paid for raising the skill of hatchery management procedures of tilapia. In some other fishes alpha-tocopherol acetate proved to be a reproductive pronoter. In rainbow trout, dietary tocopherol appeared very efficiently transferred to eggs (Sugii and Kinumaki, 1968). However body stores were sufficient to produce normal reproduction without dietary supplementation over a period of eight months before spawning (King et al., 1983). On the contrary, examining the effects of vitamin $E$ deficiency in ayu fish, Takeuchi $c^{\prime}$ al. (1981) observed abnormalities in spawning success (number of fish which spawn), in survival rate up to the eyed stage, in hatchability and survival of hatched larvae. In Red Sea bream, addition of vitamin $E$ improved the egg buoyancy and the proportion of normal larvae (Watanabe et al., 1983). In carp. a long-term o. tocopherol deficiency decreased the secretory activity of gonadotropes and brings about a delayed oocyte development (Watanabe and Takashima, 1977). These authors observed also changes in the pattern of fatty acids in triglycerides and polar lipids. In deficient ovaries, there were a decrease in $(n-6)$ and $(n-3)$ fatty 
acids and an increase in (n-9) fatty acids, a typical pattern of an essential fatty acid deficiency.

Izquierdo et al. (2001) stated that Gonadal development and fecundity of fish are affected by certain essential dietary nutrients, especially in continuous spawners with short vitellogenic periods. Elevation of dietary alpha -tocopherol levels has been found to reduce the percentage of abnormal eggs and increase fecundity in the gilthead seabream (Sparus auraica).

Lavens et cl. (1999) on turbot (Scophthalmus maximus) broodstock fed diets containing variable levels of essential fatty acid. vitamin $\mathrm{E}$ and $\mathrm{C} ; 2-3$ months prior to the reproductive season, Egg quality parameters improved in the vitamin-supplemented groups of fish. King (1985) tested the Influence of vitamin $E$ in reproduction in rainbow trout (Salmo gairdneri). The results showed that at the onset of egg maturation liver was the primary storage reservoir of alphatocopherol. At spawning most of the liver tocopherol was transferred to the ovary. During egg development, alpha-tocopherol was slowly, but efficiently transferred from the yolk to the developing embryo. Mortalities during egg development were inversely related to the alpha-tocopherol content of the eggs.

Chou and Chien (2001) investigated the effect of vitamin E on Japanese sea bass Lateolabras japonicus broodstock maintained for 35 days on diets formulated with supplementary vitamin $E$. The author found poorer egg quality and hatching performance of eggs produced from female of the control that fed without vilamin $E$ supplementation than that of females fed with vitamin $E$ supplementation.

Santiago and Gonzal(2000) studied the reproductive performance of bighead carp. Aristichthys nobilis, fed on prepared diet supplemented with different combinations of vitamin $A, E$ and $C$.

The aim of this study is to evaluate the effect of feeding Oreochromis niloricus and Oreochromis aureus broodstock with diets supplemented with different levels of $\alpha$-tocopherol acetate. 45 days prior to the spawning season. on fecundity and reproductive performance.

\section{MATERIALS AND METHODS}

In the prespawning season of tilapia.. when temperature was less than $20^{\circ} \mathrm{C}$, a number of 24 premature broodstock females of Oreochromis niloticus and 24 premature broodstock females of 


\section{EFFECT OF $\alpha$-TOCOPHEROL ACETATE ON THE REPRODUCTIVE PHYSIOLOGY OF TILAPIA}

Oreochromis culreus. 6 months old, were randomly assigned into 4 identical groups each, 6 females each. Active males were placed with the females with a ratio of $1: 3$ in each aquaria. The four groups represented a control and three treatments. Fish were accommodated in eight glass aquaria $150 \times 50 \times 50 \mathrm{~cm}$ filled with dechloronated and aerated tap water $40 \mathrm{~cm}$ depth. Average body weight of (Oreochromis. niloticus and Oreochromis cureus was $13.2 \pm 28.65 \& 123.57 \pm$ 19.39. respectively in the control group. $115.45 \pm 47.66 \& 119.52 \pm$ 23.66 in treatment $1.111 .06 \pm 20.89 \& 118.89 \pm 30.48$ in treatment 2 and $116.97 \pm 27.9 \& 116.46 \pm 20.15 \mathrm{~g}$ in treatment 3 . Fish of the control group were fed on $3 \%$ of the total biomass daily with pelleted feed $(25 \% \mathrm{CP})$. Those of treatment 1,2 and 3 were fed with $3 \%$ of the same feed. containing 5,25 and $50 \mathrm{mg} \alpha$-tocopherol acetate $\mathrm{h}$. respectively. Feces and feed detritus were siphoned off daily and the wastewater was replaced. Feeding started in all treatments 45 days before spawning and continued until all females spawned successively. Fenales were checked regularly whether they spawned or not by opening their mouths grently. Whenever a fish spawned. it was weighed, eggs were extruded from the buccal cavity, weighed. counted and incubated in Macdonald jars until hatching takes place. Hatching percentage and percentage of deformed larvae were estimated. Representative samples (triplicate numbers) from spawn of each treatment (the post-hatching larvae) were incubated in small glass aquaria. After the yolk sac absorption period the firy were collected on a filter paper to remove the wetness, weighed on a tine balance and counted to estimate the average weight per fry produced from each treatment. Blood samples were taken from the donor females of $O$. niloticus to measure the luteinizing hormone $(\mathrm{LH})$ and follicle stimulating hormone (FSH) in the serum. The Radio Immuno assey was used for this purpose. After taking the blood sample, the female was sacrificed and the remaining ovary was removed from the coelom and weighed. Gonadosomatic index was calculated.

Statistical analysis was performed using t-test according to Snedecor (1971).

\section{RESULTS}

There were no significant differences among means of Oreochromis niloticus female body weights and Oreochromis curreus in the three treatments. Also mean body weights of $O$. niloticus in the three treatments were insignificantly different than that of Oreochromis cureus in the three comparable treatments. 
The mean relative fecundity (RF) of $O$. niloticus and $O$. aureus broodstock females in treatment $3(2.8 \pm 0.51 \& 2.83 \pm 0.39$, respectively) that fed a diet contained $50 \mathrm{mg} \alpha$-tocopherol acetate $/ \mathrm{kg}$; treatment $2(2.85 \pm 0.37 \& 2.7 \pm 0.59$, respectively $)$ that fed a diet supplemented with $25 \mathrm{mg} \alpha-\mathrm{TOH} / \mathrm{kg}$ and treatment $1(2.74 \pm 0.47 \&$ $2.75 \pm 0.29$, respectively) that fed $5 \mathrm{mg} \alpha-\mathrm{TOH}$ acetate $/ \mathrm{kg}$ supplemental diet were not significantly different than that in the control group of each strain $(2.73 \pm 0.5 \& 2.68 \pm 0.39$. respectively). There were also no appreciable differences among means of (RF) in the three treatments as represented in Tables (1) and (2).

The mean number of eggs spawned by females of treatment 1 , 2, 3 and the control showed the same trend, in both species, as the mean (RF) value $333 \pm 185,323 \pm 100,338 \pm 144$ and $321 \pm 139$ eggs, respectively for $O$. niloticus and $334 \pm 99,336 \pm 150$ or $337 \pm$ 100 and $338 \pm 100$ eggs, respectively for $O$. cureus.

The mean weigh of eggs produced by females of treatment 1 $(1.6 \pm 1.02 \mathrm{~g}$, for $O$. niloticus and $1.71 \pm 1.17 \mathrm{~g}$, for $O$. curreus $)$ and treatment $2(1.97 \pm 0.77 \mathrm{~g}$, for the former and $(2.18 \pm 1.06 \mathrm{~g}$, for the later) did not differ significantly than that produced by females of the control ( $1.6 \pm 0.95$ and $1.47 \pm 0.63 \mathrm{~g}$, respectively). However females of the third treatment produced noticeably larger quantity of eggs $(2.93 \pm 0.92$ and $2.42 \pm 0.82 \mathrm{~g}$. respectively) than that produced by females of the control. $\mathrm{p}<0.05$.

Mean weight/egg of O.nilotocus in the third treatment surpassed, $p<0.001$. that in the other treatments $(8.98 \pm 1.11 \mathrm{Vs} 6.0$ $\pm 0.78,4.98 \pm 1.98$ and $4.82 \pm 1.3 \mathrm{mg}$ for the treatment 3. 2. 1 and the control. respectively). On the other hand, It didn't differ significantly' in treatment 1 and 2 than that in the control.

For $O$. aureus the mean weight/egg in the second and third treatment $(6.44 \pm 0.17$ and $7.35 \pm 1.79 \mathrm{mg}$, respectively) increased significantly than that in the control $(4.17 \pm 0.7 \mathrm{mg})$. and did not show significant difference with that in treatment $1(4.83 \pm 2.14 \mathrm{mg})$.

With regard to gonadosomatic index (GSI). females of both genera in the third treatment had significantly higher mean value of GSI; $3.7 \pm 0.46$ and $3.33 \pm 0.82 \%$, respectively: than that of the control and treatment $1(2.25 \pm 1.5 \& 2.07 \pm 1.07$ and $1.91 \pm 0.47 \&$ $2.07 \pm 0.77 \%$, respectively). Whereas neither GSI of females of the first nor the second treatment $(3.68 \pm 0.57 \& 3.1 \pm 0.79 \%)$ showed significant difference than that of the control.

Data of hatchability of $O$. niloticus and $O$. aureus revealed that the mean hatching percentage of eggs produced by females of 


\section{EFFECT OF $\alpha$-TOCOPHEROL ACETATE ON THE REPRODUCTIVE PHYSIOLOGY OF TILAPIA}

treatment $3(83.5 \pm 3.7 \& 83.0 \pm 4.0 \%)$ and by females of treatment 2 $(80.1 \pm 0.9 \& 81.1 \pm 1.1 \%)$ were significantly higher than that of eggs spawned by females of the control. $75.4 \pm 1.1 \& 76.1 \pm 1.6 \%$ (p $<0.001)$. Also the mean hatching percentage of eggs of treatment 3 was significantly higher $(p<0.01)$ than that of eggs obtained from females of treatment $1(76.0 \pm 2.1 \& 76.9 \pm 1.9 \%)$. Nevertheless, There was no observable difference of mean hatching percentage of eggs between the control \& treatment 1 and treatment $2 \&$ treatment 3.

As for the mean percentage of deformed larvae of (). niloticus. it was significantly lower in larvae of treatment 1.2 and 3 than that in the control. $4.0 \pm 0.8 .3 .2 \pm 0.9 .2 .1 \pm 0.3$ and $4.9 \pm 0.5 \%$. respectively. Whereas it was insignificantly different among lar'vae of both the first and second treatment. It was also significantly decreased in the third treatment than that in the second one, $p<0.05$.

No significant difference was detected between means of percentage of deformed larvae of 0 . currets in the first treatment $(4.5$ $\pm 0.8 \%)$ and in the control $(5.1 \pm 1.0 \%)$ and among means of first and second treatment $(3.1 \pm 0.5 \%)$ that had significant lower mean value than the control. $p<0.01$. Significant lower mean values of deformed larvae percentage were noticed in larvae of the third treatment $(2.0 \pm$ $0.3 \%$ ) than in larvae of the control and larvae of the first treatment. But in larvae of treatment 2 and 3 it was nearly the same values.

The fry produced from females of the third treatment of both species (after the yolk sac absorption period) had a higher mean body weight $(13.3 \pm 0.2 \& 13.2 \pm 0.2 \mathrm{mg} /$ fry $)$ than mean body weight of fry of the second treatment $(11.2 \pm 0.3 \& 10.9 \pm 0.3 \mathrm{mg} /$ fry $) . p<0.001$. The later was also increasingly higher than that of fry obtained from the first one $(10.1 \pm 0.4 \& 10.15 \pm 0.3 \mathrm{mg} / \mathrm{fry})$ which in it's turn had larger mean body weight than fry of the control $(9.0 \pm 0.2 \& 9.1 \pm 0.2$ $\mathrm{mg} / \mathrm{fry}$ ).

When the correlation analysis was applied on the body weight of all temales of $O$. niloticus and $O$. curreus and the corresponding number of eggs produced, irrespective of feeding regime, a highly significant correlation was found in the control and the other three treatments. The following simple linear correlation as indicated in Figure (1) gave a reasonable approximation for the number of eggs spawned in relation to the body weight, on the linear predictive regression curve:

Where $Y=$ number of eggs spawned

$$
\mathrm{Y}=\mathrm{a}+\mathrm{b} X
$$

and $X=$ weight of female brooder. 
Measuring the reproductive hormones showed that concentration of Luteinizing hormone (LH) and Follicle stimulating hormone (FSH) in serum of $O$. niloticus females of treatment 3 was higher than that in serum of females of the control, treatment land treatment 2; as illustrated in Figure (2).

\section{DISCUSSION}

It seems that the reproductive response of Oreochromis niloricus and Oreochromis cureus to vitamin E, alpha-tocopherol acetate, was nearly the same regarding egg number and quality, hatchability, gonadosomatic index and quality of the resulting offspring. However there were some negligible errors and differences due to individual variability among females and personal errors during egg collection and handling.

It is evident from the present study that none of the three levels of alpha-tocopherol acetate had any obvious effect on the mean relative fecundity of either $O$. niloticus or $O$. aureus. According to Sugii and Kinumaki (1968) and King (1985) at spawning, transfer of dietary alpha-tocopherol during egg development from the liver to the ovary and from the yolk to the developing embryo possibly influenced the quality of eggs and vitality of the resulting offspring. This could be substantiated with the data of the present study. Females that fed on a diet supplemented with $50 \mathrm{mg} \alpha$-tocopherol acetate $/ \mathrm{kg}$ produced larger eggs than females that fed diet without supplemental alpha-tocopherol (control). Moreover. larger than eggs obtained from females that fed on diets supplemented with lower levels of $\alpha-\mathrm{TOH}$. This result is in concordance with Lavens ef al. (1999) on turbot (Scophthalmus maximus) who noted also that when broodstock fed diets containing variable levels of essential fatty acid. vitamin $\mathrm{E}$ and $\mathrm{C} ; 2-3$ months prior to the reproductive season, egg quality parameters improved in the vitamin-supplemented groups of fish.

It is suspected that this may also had its reflex on the mean hatching percentage of eggs and mean percentage of deformed larvae. The highest mean hatching percentage and lowest mean percentage of deformed larvae were observed in eggs extruded from females fed 50 $\mathrm{mg} \alpha-\mathrm{TOH} / \mathrm{kg}$-supplemented diet. While lower mean values of the former and higher of the later were detectable in eggs of those females that were fed supplemental 25 and 5-mg $\alpha-\mathrm{TOH} / \mathrm{kg}$ diet. This 


\section{EFFECT OF $Q$-TOCOPHEROL ACETATE ON THE REPRODUCTIVE PHYSIOLOGY OF TILAPIA}

could be attributed to the elevated concentrations of $\alpha$-TOH in ovaries of females that fed higher $\alpha-\mathrm{TOH}$ supplemented diets. King (1865) on rainbow trout (Salmo gairdneri).elucidated also that mortalities during egg development were inversely related to the alpha-tocopherol content of the eggs. It could be concluded also that the fertilizing capability of males increased with increasing the quantity of $\alpha-\mathrm{TOH}$ in the diet that might enhanced the sperm mobility and activity, accompanied with improving the egg quality, leading to ascending mean hatching percentage and descending mean percentage of deformed larvae. The same conclusion was achieved by Chou and Chien (2001) who noticed poorer egg quality and hatching performance of eggs produced from females that fed without vitamin $E$ supplementation than that of females fed with vitamin $E$ supplementation.

The effect of o-TOH may exceeded this extent and affected the size of the hatched fry and survival rate. Fry of the third treatment attained the highest mean body weight. Mean survival rate anong them was the highesi compared to the control. The smaller sizes of fry that had lower mean survival rates were obtainable from eggs produced by females fed the lower levels of $\alpha$-TOH. Fry of females that fed tocopherol -free diet was the smallest with the lowest survival.

The data of gonadosomatic, index illustrated that the disparity in mean ovary weights among females of the three treatments may be due to the different supplementalo-TOH levels. Females that fed on diets provided with higher levels of $\alpha-\mathrm{TOH}$ not only produced larger eggs but also had higher mean values of GSI than those fed on diets with lower levels. This could be attributed to changes in the pattern of essential fatty acids due to transfer of $\alpha^{\prime}$ - $\mathrm{TOH}$ to the ovary according to Sugii and Kinumaki (1968) on rainbow trout. This result is in agreement with lzquierdo et at. (2001) who stated that gonadal development and fecundity are affected by certain essential dietary nutrients such as Lipid and fatly acids that have been identified as major dietary factors that determine successful reproduction and survival of offspring.

Irrespective of the supplemental $\alpha$-TOH levels that had no effect on the mean number of eggs/female in the three treatments, correlating the $O$. niloticus and $O$. aureus female body weight and the corresponding number of eggs, obtainable from the first spawning, showed a linear correlation. This correlation could be represented as 
indicated in Figures (1) and (2). The equation of this relationship in the first spawning is represented as follows:

$$
\mathrm{Y}=4.3353 \mathrm{X}-166.67 \quad \text { for (). niloticus }
$$

And $Y=4.7819 X-235.76 \quad$ for (). culleus

Where $Y=$ number of eggs obtained from the first spawning

$\mathrm{X}=$ female body weight.

Further investigations are needed to estimate egg production/female in the following spawning all over the reproductive period under the same conditions.

With regard to the reproductive hormones. concentration of luteinizing hormone ( $\mathrm{LH}$ ) and follicle stimulating hormone (FSH) in serum of $O$. niloficus females of the third treatment. that exhibited more active reproductive performance. was higher than that in serum of females of the other treatments and the control. This may elucidate the enhanced oogenesis of ovaries of these females that resulted in not only better quality of the eggs spawned but also higher GSI than in other treatments.

The present study is in partial agreement with Emata et al. (2000) on milkfish Chanos chanos who fed the fish formulated $136 \%$ $C P)$ ) diets supplemented with vitamin $C$, vitamin $E$ for 3 years.

The present result coincide with Izquierdo et al. (2001) who stated that in broodstock. alpha-tocopherol acetate has been shown to greatly improve not only egg and sperm quality but also gonadal development and seed production. especially in continuous spawners with short vitellogenic periods. Accordingly short-term feeding of $($ ). niloticus and $O$. alureus with $50 \mathrm{mg}$-tocopherol supplemental diet prior to the reproductive season was appropriate to raise the reproductive efficiency of both genera as they are considered continuous spawners and characterized with short vitellogenic periods.

\section{REFERENCES}

Badawy. E. A. (1993). Biological studies on Tilapia species as a major component of the Egyptian fish farming system. Ph. D. Thesis Faculty of Science. Zagazig University. 222pp. 
Chou, Y. H. and Chien, Y. H. (2001). Effects of astaxanthin and vitamin $E$ supplement in Japanese sea bass Lateolabrax japonicus brood stock diet on their fecundity and egg quality. 6th-Asian-Fisheries-Forum-Book-of-Abstracts, Unit A. pp. 60.

El-Saby, M. K. (1951). The lake fisheries of Egypt. Proc. Un. Sci. Conf. Conserv. Unil. Resource.. 7: 126-130.

Emata, A. ; Borlongan, 1. and Damaso. I. (2000). Dietary vitamin C and $E$ supplementation and reproduction of milklish Chanos chanos Forsskal. Aquaculture-Reșearch [Aquacult-Res]. 31(7):557-564.

Green, B. W. ; Veverica, K. L. and Fitzpatrick, M. S. (1997). "Fry' and Fingerling Productioni. Pp. 215-244 in H. S. Egna and C. E. Boyd editors, Dynamics of Pond Aquaculture. CRC Press, Boca Raton, Florida. USA.

Hughes D. G. and Behrends, L. L. (1983). Mass production of Tilapia nilotica seed in suspended net enclosures. International symposium on Tilapia in Aquaculture. Proceedings Nazareth Israel May 8-13.1983.394-401

Izquierdo, M. S. ; Fernandez P. H. and Tacon, A. G. J. (2001). Effect of broodstock nutrition on reproductive performance of fish. Aquacult., $197(1-4): 25-42$

King. 1. B. (1985). Influence of vitamin $E$ in reproduction in rainbow trout (Salmo gairdneri). DISS.-ABST.-INT.-PT.-B-SCl.-andENG., f6(2)185 pp.

King, 1. ; Hardy, R. W. and Halver. J. E. (1983). The effect of dietary vitamin $E$ on the distribution of $\alpha$-tocopherol in rainbow trout (Salmo gairdneri) during ovarian maturation. International Symposium on Salmonid Reproduction. 1983. Seatle (Wash.) p. 24. 
Lavens, P. ; Lebegue. E. ; Jaunet. H. ; Brunel, A. ; Dhert. P. and Sorgeloos, P. (1999). Effect of dietary essential fatty acids and vitamins on egg quality in turbot broodstocks. Aquaculture-International [Aquacult-Int]. 7(4):225-240.

Lovshin, L. L. (1998). Criteria for Selecting Nile Tilapia and Red Tilapia for Culture. Second Symposium on the Management and Nutrition of Fishes held in Piracicaba, SP. Brazil on July $22-23.1998$.

MacIntosh. D. J. and Little. D. C. (1995). "Nile Tilapia". Pp. 277320 in N. R. Bromage and R. J. Roberts editors. Broodstock Management and Egg and Larval Quality. Blackwell Science, 238 Main Street. Cambridge. Massachusetts. USA.

Mires, D. (1983). A technical evolution of tilapia culture. pp. $317-$ 329. International symposium on tilapia in aquaculture. Proceedings 624pp Tel Aviv Univ.. Israel

Santiago, C. B. ; Gonzal, A. C. (2000). Effect of prepared diet and vitamin $A, E$ and $C$ supplementation on the reproductive performance of cage-reared bighead carp Aristichthys nubilis (Richardson).I-Appl-Ichthyol; Z-Angew-Ichthyol, (6)(1):813.

Snedecor, G. W. (1971). "Statistical Methods" 14". Ed. Imes. Iwa. The Iowa State Univ. Press. 593pp.

Sugii, K. and Kinumaki, T. (1968). Distribution of vitamin $E$ in a few species of fish. Bull. Jap. Soc. Sci. Fish., 3t: 420-428.

Takeuchi, T. ; Watanabe, T. ; Ogino. C. ; Saito. M. ; Nishimura, K. and Nose, T. (1981). Effects of low protein-high calory diets and deletion of trace elements from a fish meal diet on reproduction of rainbow trout. Bull. Jap. Soc. Sci. Fish., 47: 645-654. 
Watanabe, T. ; Koizumi, T. ; Suzuki, H. ; Satoh, S. : Takeuchi. T. : Yoshida, N. ; Kitada, T. and Tsukashima. Y. (1983). Improvement of quality of Red Sea bream eggs by feeding them on cuttlefish meal diet and raw krill shortly before spawning. Ann. Meet. Jap. Soc. Sci. Fish. Oct. 1983, pp. 91.

Watanabe, T. and Takashima, F. (1977). Effect of $\alpha$-tocopherol deficiency on carp. VI. Deficiency symptoms and changes of fatty acid triglyceride distribution in adult carp. Bull. Jap. Soc. Sci. Fish., 43: 819-830. 
Table (1): Average number of eggs. mean weight of eggs. Relative fecundity, average weight/egg, gonadosomatic. index. hatching\%, percentage of deformed larvae and mean weight/fry produced from Oreochromis niloticus: broodstock females fed on three diets containing 5.25 and $50 \mathrm{mg}$ a-tocopherol acetate $/ \mathrm{kg}, 45$ days prior to the spawning season.

\begin{tabular}{|c|c|c|c|c|}
\hline & Control & Treat. 1 & Treat. 2 & Treall 3 \\
\hline No. of females & 6 & 6 & 6 & 6 \\
\hline Total wh of females (g) & 679.21 & 662.67 & 666.34 & 701.82 \\
\hline Average wrt. / female (g) & $113.2=28.65^{11}$ & $115.45 \pm 47.66^{11}$ & $111.06 \pm 20.89^{\circ}$ & $116.97 \doteq 27.9^{4}$ \\
\hline Total No of eggs & 1927 & 1997 & 1937 & 2026 \\
\hline Ave. No of eggs & $231.5 \pm 139^{3}$ & $333 \pm 185^{i 1}$ & $323 \times 100^{\prime \prime}$ & $338=1+4.8^{x}$ \\
\hline Mean wt. of eggs (g) & $1.6 \pm 0.95^{n}$ & $1.6 \pm 1.02^{\pi t}$ & $1.97 \pm 0.77^{\mathrm{in}}$ & $2.93=0.92^{13}$ \\
\hline Relative fecundity* & $2.73: 0.5^{i}$ & $2.74 \div 0.47^{11}$ & $2.85=0.37^{\circ}$ & $2.8: 11.51^{11}$ \\
\hline Ave. wt. / egg (mg) & $4.82 \div 1.3^{11}$ & $+.89 \div 1.98^{111}$ & $6.0=0.78^{: 11}$ & $68.98=1.11^{\circ}$ \\
\hline$\overline{G S I} \% \%^{* *}$ & $1.91 \pm 0.47^{115}$ & $2.25 \pm 1.5^{i 1}$ & $3.68 \pm 0.57$ 1.6 & $3.7 \pm 0.46^{\circ}$ \\
\hline Hatching percentage $\%$ & $75.4 \pm 1.1^{: 1}$ & $76.0 \pm 2.1^{\mathrm{it}}$ & $80.1 \pm 0.9^{\circ}$ & $83.5 \pm 3.7^{4}$ \\
\hline$\%$ of deformed larvae & $4.9 \pm 0.5^{-31}$ & $4.0 \pm 0.8^{i n}$ & $3.2 \pm 0.9^{11}$ & $2.1 \pm 0.3^{2}$ \\
\hline Mean wt. / fry (mg) & $9.0 \pm 0.2^{3}$ & $10.1 \pm 0.4^{6}$ & $11.2 \pm 0.3^{\circ}$ & $13.3 .10 .2^{9}$ \\
\hline
\end{tabular}

Numbers with common alphabetic letters within the same column are not significantly different.

$*$ = number of eggs/weight of female

$* *=$ ovary weight $\times 100 /$ weight of female 
Table (2): Average number of eggs, mean weight of eggs. Relative fecundity. average weight/egg, gonadosomatic index. hatching\%, percentage of deformed larvae and mean weight/fry produced from Oreochromis aureus broodstock females fed on three diets containing 5.25 and $50 \mathrm{mg}$ a-tocopherol acetate / kg. 45 days prior to the spawning season.

\begin{tabular}{|c|c|c|c|c|}
\hline & Control & Treat.' 1 & Treat 2 & Tieall. 3 \\
\hline No. of females & 6 & 6 & 6 & 6 \\
\hline Total wt. of females $(\mathrm{g})$ & 7.41 .44 & 717.1 & 713.31 & 698.78 \\
\hline Average wt. / female (g) & $123.6 \pm 19.39^{11}$ & $119.52 \pm 23.52^{n}$ & $118.89 \pm 30.48^{\circ}$ & $116.46=20.15^{\circ}$ \\
\hline Total No. of eggs & 2027 & 2005 & 2015 & 2019 \\
\hline Ave. No. of eggs & $238 \pm 100^{4}$ & $334 \pm 99^{\text {a }}$ & $336 \pm 156^{n 11}$ & $337 \pm 100^{100}$ \\
\hline Mean wt. of eggs (g) & $1.47 \pm 0.63^{\mathrm{nth}}$ & $1.71 \pm 1.17^{\mathrm{nc}}$ & $2.18 \pm 1.06^{1004}$ & $2.42 \pm 0.82$ \\
\hline Relative fecundity & $2.68 \pm 0.39^{\mathrm{a}}$ & $2.75 \pm 0.29^{11}$ & $2.7 \pm 0.59^{h}$ & $2.83 \pm 0.39 \sqrt{10}$ \\
\hline Ave.wt. / egg (mg) & $4.17 \pm 0.7^{\mathrm{n}}$ & $4.83 \pm 2.14^{n}$ & $6.44 \pm 0.17^{\prime \prime}$ & $7.35 \pm 1.79$ \\
\hline Gonadosomatic index $\%$ & $2.07 \pm 1.07^{\mathrm{it}}$ & $2.07 \pm 0.77^{1}$ & $3.1 \pm 0.79^{11}$ & $3.33 \pm 0.82^{11}$ \\
\hline Hatching percentage \% & $76.1 \pm 1.6^{\mathrm{n}}$ & $76.9 \pm 1.9^{i 1}$ & $80.1 \pm 1.1^{11}$ & $83.0 \div 4^{11}$ \\
\hline$\%$ of deformed larvae $\%$ & $5.1 \pm 1^{3}$ & $4.5 \pm 0.8 \mathrm{in}$ & $3.1 \pm 0.5^{\top}$ & $2.0 \pm 0.3^{6}$ \\
\hline Mean wl. of fry (mg) & $9.1 \pm 0.2^{n}$ & $10.15 \pm 0.3^{13}$ & $10.9 \pm 0.3^{5}$ & $13.2 \pm 0.2 \pi$ \\
\hline
\end{tabular}

Numbers with common alphabetic letters within the same column are not significantly different. 
Figure (1): Number of eggs produced from $O$. niloticus and $O$. curreus broodstock females of different sizes, regardless. of feeding regime

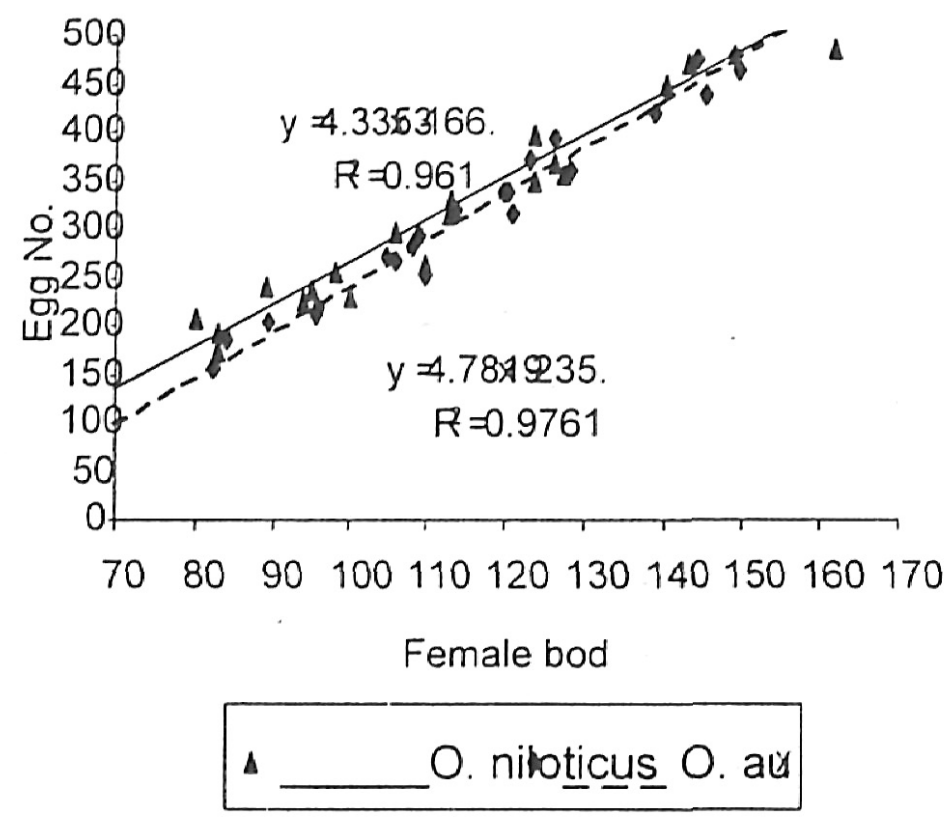

Figure (2): Concentration of Luteinizing hormone (LH) and Follicle stimulating hormone (FSH) in serum of $O$. niloticus broodstock spawners.

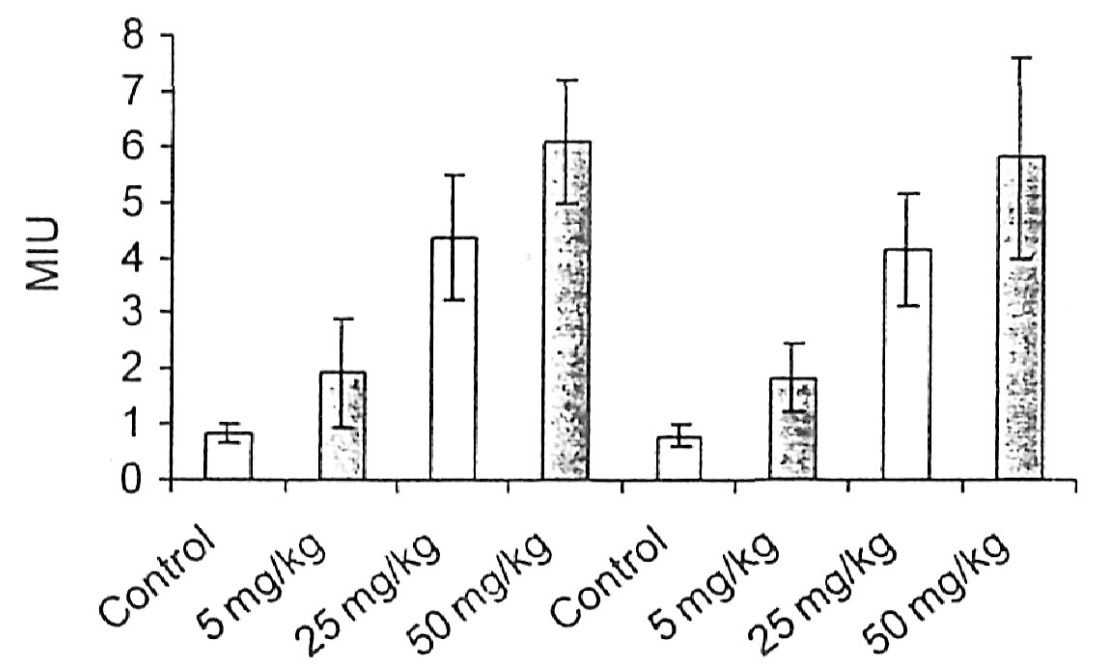

LH 